\title{
Acute pancreatitis and ileus postcolonoscopy
}

\author{
Hin Hin Ko MD FRCPC ${ }^{1,2}$, Trevor Jamieson MD², Brian Bressler MD MS FRCPC ${ }^{1,2}$
}

HH Ko, T Jamieson, B Bressler. Acute pancreatitis and ileus postcolonoscopy. Can J Gastroenterol 2009;23(8):551-553.

Postpolypectomy bleeding and perforation are the most common complications of colonoscopy. A case of acute pancreatitis and ileus after colonoscopy is described. A 60-year-old woman underwent a gastroscopy and colonoscopy for investigation of iron deficiency anemia. Gastroscopy was normal; however, the colonoscope could not be advanced beyond the splenic flexure due to a tight angulation. Two polypectomies were performed in the descending colon. After the procedure, the patient developed a distended, tender abdomen. Bloodwork was remarkable for an elevated amylase level. An abdominal $\mathrm{x}$-ray and computed tomography scan showed pancreatitis (particularly of the tail), a dilated cecum and a few air-fluid levels. The patient improved within $24 \mathrm{~h}$ of a repeat colonoscopy and decompression tube placement. The patient had no risk factors for pancreatitis. The causal mechanism of pancreatitis was uncertain but likely involved trauma to the tail of the pancreas during the procedure. Our patient developed ileus, likely secondary to pancreatitis. The present case is the first report of clinical pancreatitis and ileus associated with colonoscopy.

Key Words: Colonoscopy; Ileus; Pancreatitis

\section{Pancréatite aiguë et iléus post-coloscopie}

L'hémorragie et la perforation post-polypectomie sont les complications les plus fréquentes de la coloscopie. On décrit ici un cas de pancréatite aiguë et d'iléus consécutifs à une coloscopie. Une femme de 60 ans a subi une gastroscopie et une coloscopie exploratoires pour anémie ferriprive. La gastroscopie s'est révélée normale, mais, la coloscopie n'a pas pu être effectuée au-delà de l'angle colique gauche en raison de méandres infranchissables. Deux polypectomies ont été effectuées au niveau du côlon ascendant. Après l'intervention, la patiente a présenté un abdomen distendu et sensible. Les analyses sanguines ont révélé une augmentation du taux d'amylases. La radiographie abdominale et une tomographie ont confirmé la présence d'une pancréatite (affectant particulièrement la queue du pancréas), d'un cæcum dilaté et de quelques niveaux hydroaériques. L'état de la patiente s'est amélioré 24 heures après une reprise de la coloscopie avec pose de tubes de décompression. La patiente ne présentait aucun facteur de risque de pancréatite. Le mécanisme causal de la pancréatite est incertain, mais pourrait découler d'un traumatisme infligé à la queue du pancréas durant l'intervention. Notre patiente a développé un iléus, probablement secondaire à la pancréatite. Il s'agit du premier rapport de cas de pancréatite clinique et d'iléus associés à la coloscopie.
$\mathrm{C}$ Oolonoscopy is a widely used diagnostic and therapeutic intervention, and is generally well tolerated. Potential complications include postpolypectomy bleeding, perforation and side effects related to sedation and analgesia (1-3). Acute pancreatitis, a well-documented complication of endoscopic retrograde cholangiopancreatography (4), is generally not considered to be a complication associated with an endoscopic procedure that does not involve ampullary cannulation. A case of acute pancreatitis and ileus after colonoscopy is described.

\section{Clinical history}

\section{CASE PRESENTATION}

A 60-year-old Caucasian woman with a previous cadaveric renal transplant for hypertensive nephropathy underwent a gastroscopy and colonoscopy for investigation of iron deficiency anemia. The patient was otherwise healthy and without a history of gastrointestinal symptoms or disease. She rarely consumed alcohol and had a 15 pack-year smoking history. Her regular medications included tacrolimus, mycophenolate mofetil, labetalol, prednisone and diltiazem. All medications were started and doses were stable for at least six months before her endoscopic procedures.

The patient was premedicated with midazolam and fentanyl, and the gastroscopy was normal. However, the colonoscopy was technically difficult. The colonoscope would not advance beyond the splenic flexure despite multiple repositioning manoeuvres and the application of external pressure. The colonoscope was withdrawn and a gastroscope was inserted; however, the gastroscope also could not be passed beyond the same region. Two polyps in the descending colon, both approximately $6 \mathrm{~mm}$ in size, were removed by snare coagulation without complications. Almost immediately after the procedure, the patient developed generalized cramping and mid-abdominal pain. She was observed in the endoscopy unit for a few hours before being discharged home. The pain persisted and she returned to the hospital the next morning for assessment. She was nauseous and had not eaten after the procedure. There was no feculent or bilious vomitus. She had minimal flatus and could not pass any bowel movements.

On physical examination, the patient's blood pressure was $180 / 70 \mathrm{mmHg}$, pulse 80 beats/min and regular, and without any orthostatic changes. She was afebrile and her oxygen saturation was $97 \%$ on room air. Cardiovascular and respiratory examinations were normal. Her abdomen was markedly distended, tympanic and diffusely tender. There was no evidence of abdominal rigidity, guarding, rebound or percussion tenderness. Bowel sounds were present but scant. She had no hepatomegaly or splenomegaly, and her rectal examination was normal. The remainder of the examination was unremarkable.

Laboratory investigations revealed a hemoglobin level of $106 \mathrm{~g} / \mathrm{L}$ (normal range $120 \mathrm{~g} / \mathrm{L}$ to $155 \mathrm{~g} / \mathrm{L}$ ), a white blood cell count of $17.6 \times 10^{9} / \mathrm{L}$ (normal $4.0 \times 10^{9} / \mathrm{L}$ to $11.0 \times 10^{9} / \mathrm{L}$ ),

\footnotetext{
${ }^{1}$ Division of Gastroenterology, ${ }^{2}$ Department of Medicine, University of British Columbia, Vancouver, British Columbia

Correspondence: Dr Brian Bressler, University of British Columbia, 770-1190 Hornby Street, Vancouver, British Columbia V6Z 2 K5.

Telephone 604-688-6332,fax 604-689-2004,e-mail brian_bressler@hotmail.com

Received for publication September 17, 2008. Accepted September 26, 2008
} 


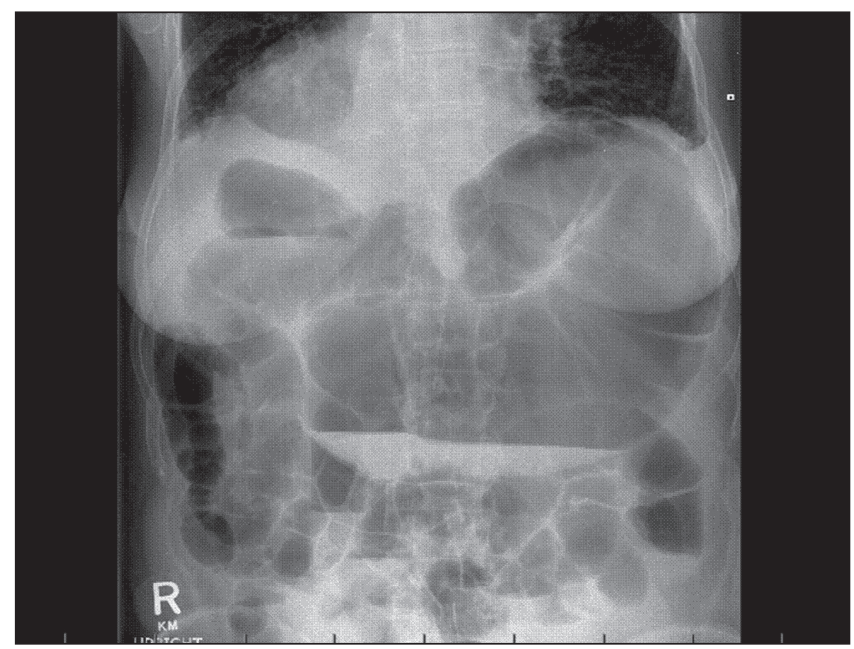

Figure 1) Abdominal x-ray revealing distension of the small and large bowel

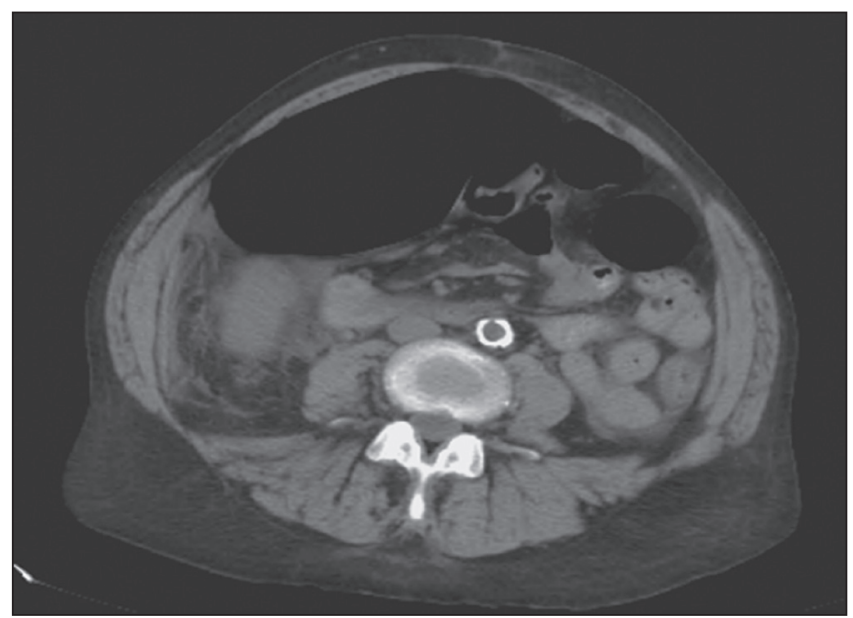

Figure 2) Abdominal computed tomography scan revealing an enlarged pancreatic tail with associated mesenteric stranding, consistent with pancreatitis

neutrophils at $16.0 \times 10^{9} / \mathrm{L}$ (normal $2.0 \times 10^{9} / \mathrm{L}$ to $8.0 \times 10^{9} / \mathrm{L}$ ), platelets at $244 \times 10^{9} / \mathrm{L}$ (normal $150 \times 10^{9} / \mathrm{L}$ to $400 \times 10^{9} / \mathrm{L}$ ), creatinine of $132 \mu \mathrm{mol} / \mathrm{L}$ ([which was the patient's baseline] normal $50 \mu \mathrm{mol} / \mathrm{L}$ to $95 \mu \mathrm{mol} / \mathrm{L}$ ), amylase $511 \mathrm{U} / \mathrm{L}$ (normal $30 \mathrm{U} / \mathrm{L}$ to $105 \mathrm{U} / \mathrm{L}$ ), aspartate aminotransferase $19 \mathrm{U} / \mathrm{L}$ (normal $10 \mathrm{U} / \mathrm{L}$ to $40 \mathrm{U} / \mathrm{L}$ ), alanine aminotransferase $14 \mathrm{U} / \mathrm{L}$ (normal $5 \mathrm{U} / \mathrm{L}$ to $45 \mathrm{U} / \mathrm{L}$ ), alkaline phosphatase $52 \mathrm{U} / \mathrm{L}$ (30 U/L to $105 \mathrm{U} / \mathrm{L}$ ), gamma-glutamyl transferase $24 \mathrm{U} / \mathrm{L}$ (normal less than $43 \mathrm{U} / \mathrm{L}$ ), total bilirubin $11 \mu \mathrm{mol} / \mathrm{L}$ (normal less than $20 \mu \mathrm{mol} / \mathrm{L}$ ) and lactate $0.9 \mathrm{~mol} / \mathrm{L}$ (normal $0.5 \mathrm{~mol} / \mathrm{L}$ to $2.1 \mathrm{~mol} / \mathrm{L}$ ). Calcium and triglycerides were normal. An abdominal $\mathrm{x}$-ray (Figure 1) showed multiple dilated loops of both the small and large bowel, with a few air-fluid levels. The cecum was distended to $12 \mathrm{~cm}$ at maximal diameter and gas was not seen in the rectum. Three views did not show any free air suggestive of perforation.

A computed tomography scan of the patient's abdomen confirmed the x-ray findings of an ileus with air-fluid levels. The colon was enlarged from the cecum to the area of nonspecific thickening at the splenic flexure. Adjacent to this bowel segment was an enlarged pancreatic tail with significant mesenteric stranding and free fluid consistent with pancreatitis (Figure 2).

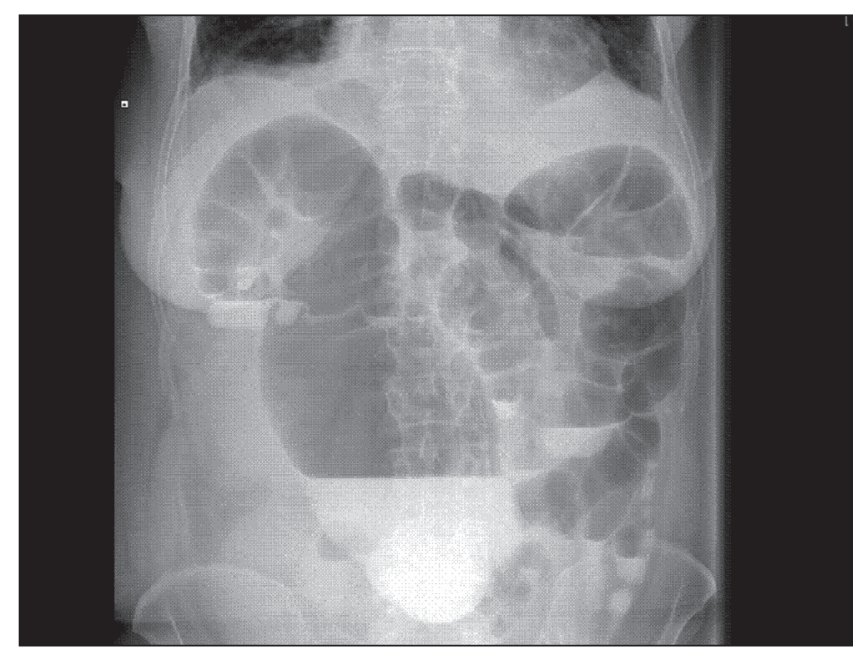

Figure 3) Abdominal x-ray showing the cecum dilated three days after colonoscopy. Multiple air-fluid levels were present in the colon and in nondilated loops of small bowel, suggestive of ileus

The patient refused nasogastric tube insertion. She was treated conservatively with bowel rest, intravenous fluids and prophylactic antibiotics. The patient's amylase levels decreased during the next few days to $225 \mathrm{U} / \mathrm{L}$; however, there was minimal clinical and radiological improvement (Figure 3). On day 3 of hospital admission, a repeat colonoscopy was performed and a colonic decompression tube was placed. Full colonoscopy was completed and revealed only mild ischemic changes in the ascending colon with no other structural abnormalities. Within $24 \mathrm{~h}$, the patient had considerable relief of her symptoms and began to pass flatus. During the next two days, her diet was successfully advanced and she was discharged home. The follow-up abdominal $\mathrm{x}$-ray revealed resolution of the ileus. Interestingly, the amylase level one day after the repeat colonoscopy increased to $406 \mathrm{U} / \mathrm{L}$ (normal $30 \mathrm{U} / \mathrm{L}$ to $105 \mathrm{U} / \mathrm{L}$ ) with resolution thereafter.

\section{DISCUSSION}

Although the colonoscopy and pancreatitis may have been coincidental, the temporal relationship of the two suggests a causal relation. Furthermore, the patient had none of the usual etiological factors associated with pancreatitis (eg, alcohol consumption, cholelithiasis, hypercalcemia or hypertriglyceridemia). In addition, none of the medications the patient was taking have been associated with acute pancreatitis.

The likely underlying mechanism of pancreatitis following colonoscopy is blunt trauma to the pancreas. Because the tail of the pancreas is in close proximity to the splenic flexure, manipulation of the colonoscope through the flexure with sufficient insufflation would produce pressure trauma to the pancreas tail. One other possible explanation is that cauterization during polypectomy may have caused a transmural colonic burn that may have resulted in pancreatic irritation - as has been suggested in a previous report (5). Our patient's ileus was not the typical retained air expected after a colonoscopy because of its persistence over many days. Her ileus was likely secondary to acute pancreatitis.

Low-grade pancreatitis after endoscopy or colonoscopy may be more common than previously reported. Previous studies 
(6) reported that asymptomatic hyperamylasuria occurred in $6.6 \%$ of patients undergoing endoscopy. Hyperamylasemia has been reported in $12 \%$ of patients undergoing endoscopy $(7,8)$ but is thought to be secondary to increased secretion of the salivary isoenzyme of amylase. Clinical pancreatitis was absent in all of these cases (6-8). There are three published reports of acute pancreatitis after upper endoscopy without ampullary cannulation: one was related to a technically difficult endoscopy (9), the second (10) was related to endoscopic ultrasound and the third (11) was associated with double-balloon enteroscopy. There has been only one reported case of pancreatitis postcolonoscopy (12). A healthy 25-year-old man underwent colonoscopy for evaluation of weight loss and diarrhea. The procedure was technically difficult and the colonoscope initially could not be advanced beyond the splenic flexure. Eventually, with withdrawal and reinsertion, the colonoscope was advanced to the cecum and a sessile polyp $5 \mathrm{~mm}$ in size was removed from the sigmoid colon. The patient experienced severe abdominal pain $4 \mathrm{~h}$ after the procedure. Laboratory evaluation revealed an

\section{REFERENCES}

1. Ghazi A, Grossman M. Complications of colonoscopy and polypectomy. Surg Clin North Am 1982;62:889-96.

2. Vernaria AM, Longo WE. Complications of endoscopic polypectomy. Surg Oncol Clin North Am 1996;5:663-73.

3. Hart R, Classen M. Complications of diagnostic gastrointestinal endoscopy. Endoscopy 1990;22:229-33.

4. Bilbao MK, Dotter CT, Lee TG, et al. Complications of endoscopic retrograde cholangiopancreatography (ERCP): A study of 10,000 cases. Gastroenterology 1976;70:314-20.

5. Nevins AB, Keeffe EB. Acute pancreatitis after gastrointestinal endoscopy. J Clin Gastroenterol 2002;34:94-5.

6. Blackwood WD, Vennes JA, Silvis SE. Post-endoscopy pancreatitis and hyperamylasuria. Gastrointest Endosc 1973;20:56-8.

7. Lifton L, Brooks C, Rosson R, et al. The effect of UGI endoscopy on serum amylase. Gastroenterology 1975;68:936. elevated amylase level of $284 \mathrm{U} / \mathrm{L}$ (normal $19 \mathrm{U} / \mathrm{L}$ to $79 \mathrm{U} / \mathrm{L}$ ) and lipase of $1525 \mathrm{U} / \mathrm{L}$ (normal $23 \mathrm{U} / \mathrm{L}$ to $208 \mathrm{U} / \mathrm{L}$ ). Acute pancreatitis was evident on an abdominal computed tomography scan. With conservative management, the patient improved during the next few days. The present case is unique because our patient developed both pancreatitis and ileus after the colonoscopy.

\section{CONCLUSION}

Patients developing postendoscopy abdominal pain require evaluation to rule out causes such as perforation. Pancreatitis and ileus should also be considered in the differential diagnosis after more common explanations are excluded. Although uncommon, the present case illustrates that it is possible for a patient without preexisting risk factors to develop pancreatitis following colonoscopy. We suspect that difficulty in advancing a colonoscope past the splenic flexure may result in trauma to the pancreas. It may be necessary to discuss the potential for this complication with patients when obtaining informed consent for colonoscopy.

8. Kobayahsi T, Fukuchi S, Sawano S, et al. Changes in serum isoamylase activities after fibergastroduodenoscopy and colonoscopy. Isoamylase after FDGS and FCS. Endoscopy 1979;11:133-7.

9. Deschamps JP, Allemand H, Janin Magnificat R, et al. Acute pancreatitis following gastrointestinal endoscopy without ampullary cannulation. Endoscopy 1982;14:105-6.

10. Kulling D, Suhai AV, Knopple WL, et al. Diagnostic endoscopic ultrasound of the pancreas may cause acute pancreatitis. Endoscopy 1998;30:S7-8.

11. Honda K, Mizutani T, Nakamura K, et al. Acute pancreatitis associated with peroral double-balloon enteroscopy: A case report. World J Gastroenterol 2006;12:1802-4.

12. Thomas AW, Mitre RJ. Acute pancreatitis as a complication of colonoscopy. J Clin Gastroenterol 1994;19:177-8. 


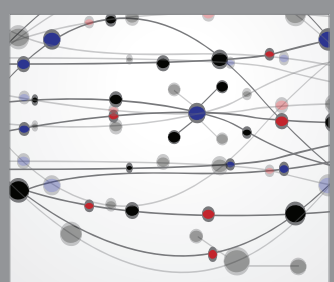

The Scientific World Journal
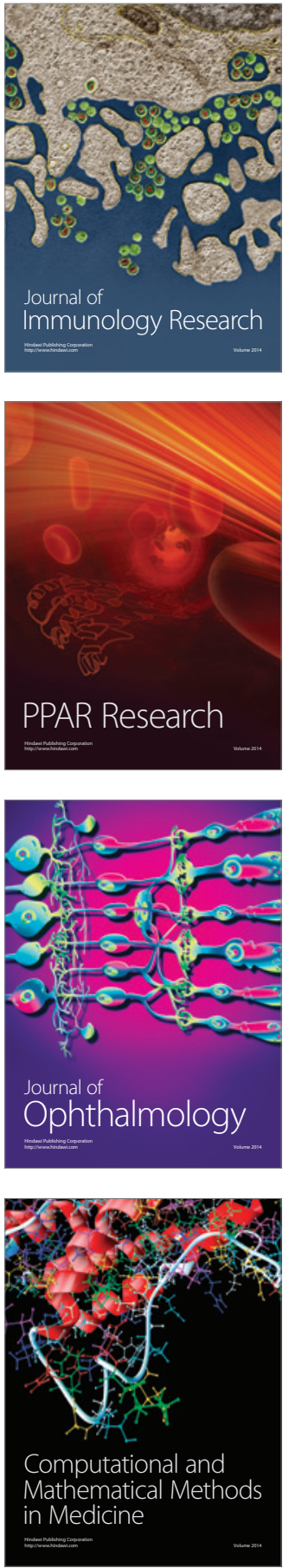

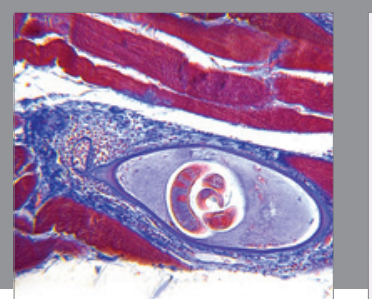

Gastroenterology Research and Practice

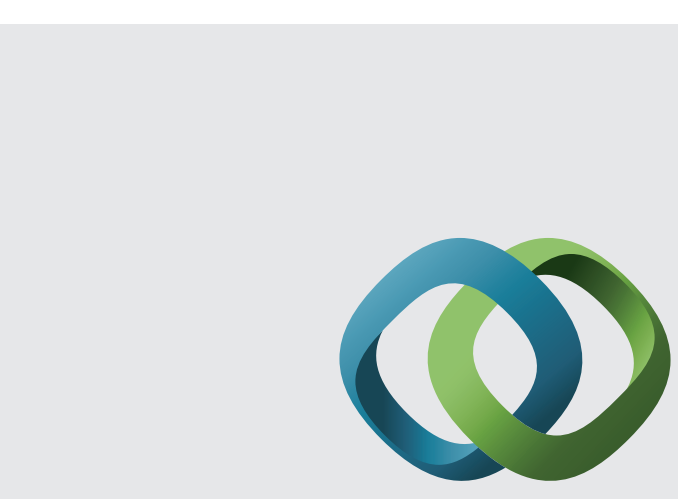

\section{Hindawi}

Submit your manuscripts at

http://www.hindawi.com
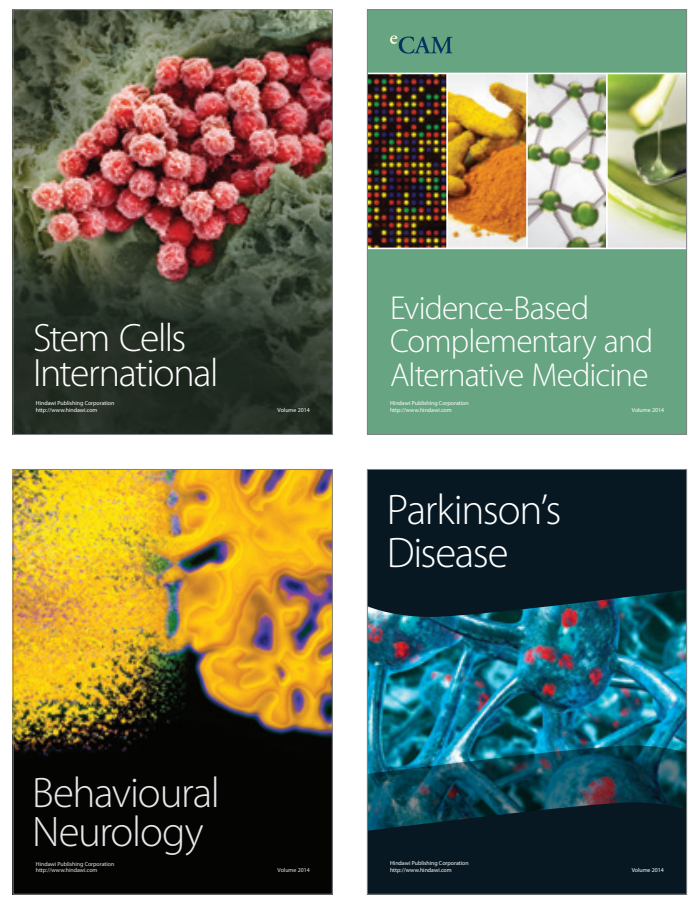
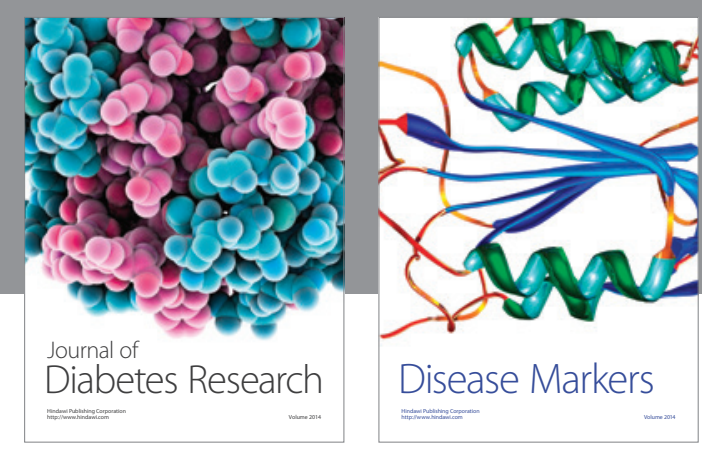

Disease Markers
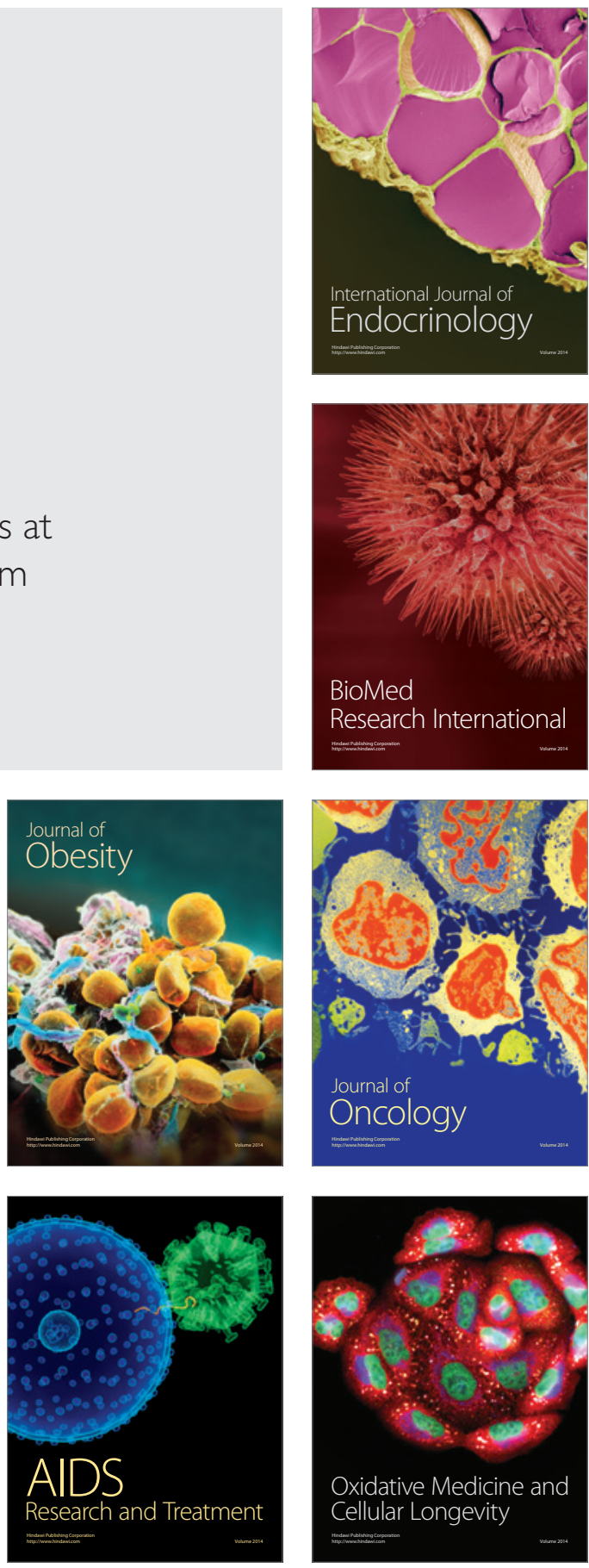